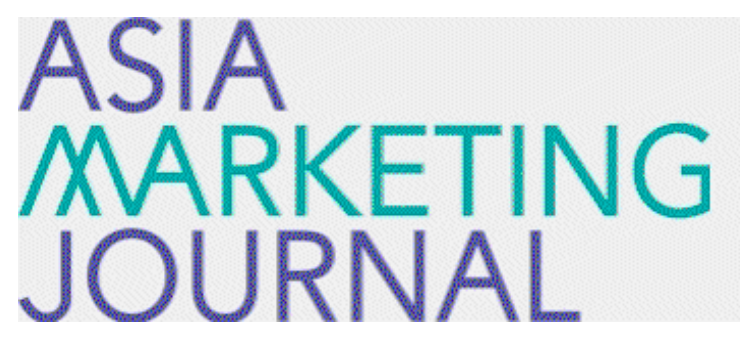

ASIA MARKETING JOURNAL

Volume 13 | Issue 3

Article 12

10-30-2011

\title{
기아자동차 $\mathrm{K} 5$ 의 포지셔닝 성공사례
}

Ji Young Seo

Doo Hee Lee

Jong Ho Lee

Jeon

Follow this and additional works at: https://amj.kma.re.kr/journal

Part of the Marketing Commons

\section{Recommended Citation}

Seo, Ji Young; Lee, Doo Hee; Lee, Jong Ho; and Jeon (2011) "기아자동차 K5의 포지셔'닝 성공사례," Asia Marketing Journal: Vol. 13 : Iss. 3 , Article 12.

Available at: https://doi.org/10.53728/2765-6500.1296

This Article is brought to you for free and open access by Asia Marketing Journal. It has been accepted for inclusion in Asia Marketing Journal by an authorized editor of Asia Marketing Journal. 


\title{
기아자동차 $\mathrm{K} 5$ 의 포지셔닝 성공사례 \\ - 변화하는 시장을 이해하고 주도하다 -
}

\section{Successful Positioning Strategy of KIA K5 - by understanding market needs -}

\author{
서 지 영 (Seo, Jiyoung)* \\ 이 두 희(Lee, Doo-Hee $)^{* * *}$ \\ 이 종 호(Lee, Jong-Ho)*** \\ 전 기 흥(Jeon, Ki Heung) $)^{* * * *}$
}

본 사례는 중형차 시장의 선도 브랜드인 기아자동차 $\mathrm{K} 5$ 가 어떻게 중형차 시장에 성공적으로 포지 셔닝 하였는지를 분석하고 있다. 기아자동차가 $\mathrm{K} 5$ 를 출시하기 전까지 쏘나타와 $\mathrm{SM} 5$ 는 각 브랜드를 선호하는 고객들의 지지를 기반으로 중형차 시장에서 1,2 위를 다투면서 오랫동안 소비자의 사랑을 독차지해 왔다. 경쟁사들이 지속적으로 새 브랜드나 신 모델을 출시함에 따라 쏘나타와 SM5도 새로 운 버전의 차를 출시해야 한다는 압박을 받게 된다. 하지만, 시장의 새로운 트랜드를 따라 잡기위해 출시된 YF 쏘나타는 기존 디자인에 비해 너무나 달라 이질감을 느끼게 하였으며, New SM5는 달라 진 것이 거의 없는 구형차 라는 이미지로 받아들여졌다. 두 브랜드가 고객들을 제대로 만족시키지 못 하고 있을 때, 기아자동차 K5는 중형차 소비자를 만족시킬 수 있는 제품에 대한 기회를 포착하고 중 형차 시장에서 현재 제공되는 가치와 소비자들이 원하는 가치의 차이를 채워줌으로써 준중형 고객의 업그레이드 수요와 중형차 대체 수요를 만족시키는 성과를 거두었다. K5는 고객들이 원하는 가치를 찾고 그 가치를 성공적으로 제안하였다. 본 사례는 포화상태에 있는 자동차 산업에서 성공적인 포지 셔닝 전략을 통해 신 시장을 개척하는 과정을 잘 보여주고 있다. 기아자동차 $\mathrm{K} 5$ 의 성공적인 포지셔 닝 전략을 크게 디자인 혁신, 시장분석, STP, 그리고 출시전략의 4 가지 축으로 설명하고 있다. 기아 자동차 $\mathrm{K} 5$ 의 성공적인 포지셔닝 전략은 신 시장 개척을 위한 포지셔닝 전략을 계획하고 있는 많은 기업에게 의미 있는 시사점을 제공해 준다.

핵심개념: 디자인 경영, 포지셔닝 전략, 가치제안

고려대학교 경영대학 박사과정(ippeni@hanmail.net)

** 고려대학교 경영대학 교수(dhlee@korea.ac.kr)

*** 고려대학교 경영대학 부교수(jongholee@korea.ac.kr), 교신저자

**** 전주대학교 경영대학 부교수(khjeon@ jj.ac.kr) 


\section{I. 서 론}

2010년 5월, 중형차 시장에 새로운 지각변동 이 일어났다. 다년간 중형차 시장점유율 1 위를 굳건히 지키던 현대자동차 쏘나타의 아성이 무 너졌기 때문이다. 쏘나타뿐만 아니라 시장점유 율 2위인 $\mathrm{SM} 5$ 의 출고실적도 크게 앞지르며 등 장한 주인공은 기아자동차의 $\mathrm{K} 5$ 였다. $\mathrm{K} 5$ 는 출시 1 달 만에 중형차 시장 1,2 위인 쏘나타와 SM5 를 큰 차이로 제치고, 출고 및 계약 실적부문에 서 1 위를 차지하며 중형차 시장의 새로운 강자 로 떠올랐다(〈표 1〉참조).

$\mathrm{K} 5$ 가 중형차 시장에서 돌풍을 일으킨 정황은 단순히 판매량에만 국한된 것이 아니다. 기존의 구매자뿐만 아니라, 중형차량의 잠재 구매 의향 자들을 대상으로 브랜드 태도를 묻는 조사에서 도 $\mathrm{K} 5$ 는 경쟁차량들을 물리치고 브랜드태도지 수 부문 1위에 선정되었다(TNS Korea, 2010). 이를 통해 $\mathrm{K} 5$ 는 중형차 시장에서 명실상부 새 로운 강자가 되었음을 엿볼 수 있다. 그렇다면 $\mathrm{K} 5$ 가 출시와 동시에 중형차 시장에서 돌풍을 일으키게 된 이유는 무엇일까? 이는 디자인 경 영철학을 기반으로 한 혁신적이고 세련된 디자 인, 철저한 시장분석을 통해 수립된 제품 개발 및 런칭 전략의 유기적 결정체라 할 수 있다. 본 사례연구에서는 $\mathrm{K} 5$ 성공의 결정적인 요인
네 가지에 대해 소개하고자 한다.

\section{II. 성공 결정요인}

\section{1 혁신적이고 세련된 디자인}

$\mathrm{K} 5$ 의 주요 성공요인인 혁신적이고 세련된 디 자인은, 기아자동차가 전사적 차원에서 강조한 '디자인 경영철학'에 기반을 두고 있다. 현대자 동차 정의선 부회장은 기아자동차 사장으로 역 임할 당시 기아자동차 브랜드 이미지의 독창성 과 차별화를 확고히 구축하기 위한 방안으로 ‘디자인 경영’을 도입하였다. 당시, 아우디 TT 를 디자인한 독일의 유명 자동차 디자이너인 피터 슈라이어를 전격적으로 최고 디자인 책임 자(CDO: Chief Design Officer)로 영입하면서 기아자동차의 디자인 경영은 닺을 올렸다.

여기서 디자인 경영이란 단순히 제품의 디자 인을 강조한다는 의미 이상을 지닌다. 〈그림 1〉 에서 호기심을 나타내는 물음표 '?'와 반짝이는 전구로 해결책을 상징화한 것을 통해 엿볼 수 있듯이, 디자인 경영철학을 통해 고객이 원하는 자동차에 대해 끊임없는 호기심과 열정을 바탕 으로 명확한 해결책을 찾고자 하며, 변화와 혁 신의 마인드(Design Thinking)와 창의적인 행

〈표 1〉국내 중형차 출고 실적

(단위: 대)

\begin{tabular}{c|rrrr}
\hline & 2010년 6월 & 2010년 7월 & 2010년 8월 & 2011년 1월 \\
\hline \hline K5 & 15,600 & 15,301 & 13,925 & 10,191 \\
SM5 & 10,921 & 9,290 & 9,003 & 8,698 \\
쏘나타 & 5,385 & 5,307 & 8,068 & 4,996 \\
\hline
\end{tabular}




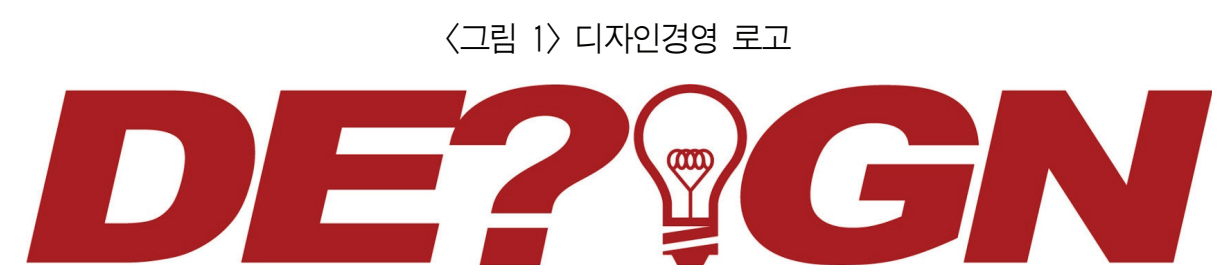

동 방식(Design Acting)을 갖추고자 하였다. 또한 기아자동차의 디자인 경영철학은 정의선 부회장의 이전 인터뷰 내용을 통해서도 확인 이 가능하다. '디자인은 단순히 차를 드로잉 (drawing)하는 것이 아니라 기업 문화를 바꾸 는 것이다라고 하였다. 좋은 디자인의 차가 나 올 수 있기 위해서는 직원들의 의사 결정 프로 세스, 가치관, 사고방식 등의 업그레이드가 필 요하기 때문이다. 즉 직원들 간 커뮤니케이션이 잘 되고, 수직적인 조직 문화를 벗어날 때 직원 들의 창의력이 적극적으로 발현될 수 있으며, 결과적으로 좋은 디자인의 차가 나올 수 있다 고 판단하였다. 궁극적으로 정부회장은 디자인 을 통해 조직 내부의 문화를 바꾸고자 시도한 것이었다.

이러한 디자인 경영철학에 따라, 기아자동차 는 선행 디자인 연구에 많은 노력을 기울이게 된다. 선행 디자인 연구는 향후 미래시장의 소 비자 트랜드를 예측하는 것을 목표로 하였다. 소비자가 미래에 관심 가질 트랜드가 무엇인지 문화, 예술, 철학적 측면뿐만 아니라 감성적인 측면의 연구가 진행되었다. 또한 기아자동차 고 유 디자인 요소를 개발하고 이를 제품에 접목 시킴으로써, 기아자동차 고유 디자인이 녹아있 는 최적 상품을 제안하고자 하였다. 즉 기아자 동차만의 내적 가치가 투영된 고유 디자인을 통해 기아자동차의 독창성을 소비자에게 각인 시키고자 한 것이다. 소비자들이 기아자동차에 대
해 신뢰하고(trustworthy), 역동적이며(dynamic) 이며 유쾌(fun)함을 인식할 수 있도록, 흥미롭 고 가능함(exciting \& enabling)을 핵심 디자인 컨셉 목표로 삼았다. 디자인 경영의 궁극적인 지향점은 고객이 원하는 가치를 제공하는 것이 며, 연구개발, 상품, 마케팅, 서비스가 융합된 고객 최우선 경영의 실천으로 볼 수 있다. 이와 같은 디자인 경영철학을 기반으로 한 노력의 결정체가 $\mathrm{K} 5$ 이며, 이는 $\mathrm{K} 5$ 성공의 중점적인 토 대가 되었다.

\section{2 시장 분석}

시장분석 단계에서는 $3 \mathrm{C}$ 에 해당하는 경쟁자 (Competitor), 소비자(Customer), 자사(Company) 중심의 분석이 이루어졌다.

국내 중형차 시장의 규모는 연간 약 25 만대의 판매량을 기록하며, 전체 승용차 4 대 중 1 대를 차지하고 있다. 현대자동차, 르노삼성, GM대우, 그리고 기아자동차 4 개 주요 중형차 제조사가 경쟁하고 있으며, 2010년 기준으로 YF 쏘나타 와 $\mathrm{New} \mathrm{SM} 5$ 가 2강 체제를 유지하고 있었다. 특히 $\mathrm{K} 5$ 의 주요 경쟁차종인 $\mathrm{YF}$ 쏘나타는 혁신 적인 스타일 및 상품성에 있어서 높은 평가를 받았으며, 현대 및 쏘나타 브랜드에 대한 높은 고객 충성도를 바탕으로 중형차 시장을 선도하 였다. 그러나 급격한 디자인 스타일 변화와 출 시 초기 품질 불만으로 인해 기존 쏘나타 선호 
고객층이 이탈하는 현상도 확인되었다. SM5의 경우 차량의 안정성을 내세우면서 쏘나타와 차 별화된 이미지를 통해 중형차 시장에서 2 위를 지켜왔다. 그러나 New SM5의 경우, 디자인과 엔진이 구형이라는 점과 다양한 사양들을 옵션 화함으로써, 기존 SM5 선호 고객층의 불만족 을 유발하였다. 즉, $\mathrm{YF}$ 쏘나타는 지나치게 혁 신적인 디자인, 반면 $\mathrm{New} \mathrm{SM} 5$ 는 보수적이고 변화가 거의 없는 고루한 느낌의 디자인이라는 점에서, 주요 중형차종 간의 스타일 차이가 극 단적인 양상을 띠고 있다고 평가되었다.

시장조사 결과, 중형차종에 대한 기존 및 잠 재적인 주요 소비자들은 35 49세의 중·장년층 으로 확인되었다. 이들은 사무직 또는 자영업을 하고 있는 중산층으로 파악되었으며, 기존의 준 중형/중형 차량들을 대체할 수 있는 새로운 차 종을 원하고 있음을 확인할 수 있었다. 이들은 젊은 감각의 라이프스타일과 개방적인 사고를 가지고 있으며, 인터넷과도 친숙하므로 원하는 차량 정보들에 대해서도 관련된 지식을 상당 수준 갖추고 있는 것으로 파악되었다. 즉 중형 차종의 고객들은 '스마트한 고객'으로 파악되며, 스타일뿐만 아니라 차량의 품질 및 연비에 대 한 높은 수준의 니즈를 충족시킬 수 있는 제품 을 원하고 있었다. 또한 중형차급의 고객들은 기존의 중형/준중형 차종을 대체하거나 추가로 구입하고자 하는 의사가 $91.6 \%$ 에 달하는 것으 로 파악됨에 따라, 시장 잠재력 또한 상당히 클 것으로 파악되었다.

자사(Company) 분석을 통해, 기아자동차는 완성도 높은 스타일과 동급 최강의 성능 및 편 의사양과 관련된 소비자 니즈를 충족시킬 만한 충분한 역량을 갖추고 있다고 평가되었다. 그러
나 경쟁차종들과 비교할 때 상대적으로 브랜드 경쟁력이 약하다는 점이 지적되었다. 디자인 경 영을 통해 기아자동차 브랜드 이미지가 확연히 개선되었으나, 향후 브랜드 이미지 향상을 위한 노력이 지속적으로 필요하다는 점이 지적되었다.

\section{$2.3 \mathrm{STP}$}

시장 분석을 통해 파악된 특성들을 바탕으로 시 장세분화(Segmentation)와 목표 고객(Targeting) 선정을 하고, 이들을 공략하기 위한 포지셔닝 (Positioning) 전략을 수립하였다.

중형차 시장에서 $\mathrm{K} 5$ 의 표적 고객은 신감각과 열린 사고를 지닌 30대 중반-40대 후반의 중산 층이다. 〈그림 2〉에서 볼 수 있듯이, 경쟁차종 인 $\mathrm{YF}$ 쏘나타는 세단보다는 쿠페 (coupe)와 같 은 스타일로의 변화로 기존 세단형을 원하는 소비자들의 니즈를 만족시키지 못하였다. 또한 급격하게 혁신적인 디자인을 채택함에 따라 이 와 같은 스타일에 익숙하지 않은 기존 충성 고 객층에게도 어필하지 못한 문제점이 야기되었 다. New SM5의 디자인은 구형디자인 요소들 을 강조함에 따라 보수적이고 진부한 이미지로 인식되었다. 젊은 감각과 세련된 중형차의 이미 지를 원하는 소비자들의 니즈를 충족시키기에 는 부족한 것으로 판단되었다. 혁신적인 디자인 요소들과 함께 세단 특유의 클래식한 스타일도 적절하게 융합함으로써, $\mathrm{K} 5$ 는 경쟁차종과 차별 화된 정체성을 가지면서 기존 중형차 시장의 고객들도 흡수할 수 있도록 포지셔닝을 취하였 다. 즉, 점진적으로 $\mathrm{New} \mathrm{SM} 5$ 및 $\mathrm{YF}$ 쏘나타가 차지한 시장의 고객층도 흡수하고자 포지셔닝 전략을 취하고자 하였다. 
위와 같은 포지셔닝을 취하기 위해 $\mathrm{K} 5$ 는 '국 내 중형차 시장의 패러다임을 바꿀 수 있는' 획 기적인 스타일과 상품성을 지닌 차량으로 개발 하고자 하였다. 스타일 측면에서는 세련되고 차 별화된 스타일을 제시함과 동시에 역동적이면 서 카리스마 있는 느낌을 살리고자 하였다. 기 존 세단들에 비해 긴 후드와 짧은 데크 길이로 스포티한 감성을 외관으로 표현하고자 하였으 며, 운전자 중심의 인터페이스와 신기술이 집약 된 인테리어 디자인이 이루어졌다. 또한 성능과 기술력 측면에서는 파워풀한 동력성능과 최고
의 연비로 수입차를 능가하는 평가를 받고자 하였다(〈표 2〉 참조). 특히 국내차종에는 본격 적으로 도입되지 않았던 안정성과 편의를 위한 하이테크 신 사양들도 적극적으로 도입하였다. 차량 출발 시 핸들이 정렬되지 않은 경우 정렬 할 것을 권고하는 '슈퍼비전 클러스터' 기능, 고 분자 코팅 및 은성분이 함유된 원단을 적용한 '바이오케어 온열 시트' 기능이 그 예가 된다.

또한 K5의 효과적인 포지셔닝을 위해 '뉴로 마케팅'기법이 활용되었다. ‘뉴로마케팅’은 뇌 과 학의 최신 기법을 이용하여 출시될 제품에 대

〈표 2〉 성능비교

\begin{tabular}{l|c|c|c|c|c|c}
\hline \multicolumn{1}{c|}{ 성능 } & \multicolumn{2}{|c|}{$\mathrm{K} 5$} & 캠리 & 알티마 & 어코드 & 뉴M5 \\
\hline \hline 엔진 배기량 $(\ell)$ & 2.0 & $2.4 \mathrm{GDi}$ & 2.5 & 2.5 & 2.4 & 2.0 \\
최고 출력 $(\mathrm{ps})$ & 165 & 201 & 175 & 170 & 180 & 141 \\
최대 토크 $(\mathrm{kg} \cdot \mathrm{m})$ & 20.2 & 25.5 & 23.6 & 24.2 & 22.6 & 19.8 \\
연비 $(\mathrm{km} / \ell)$ & 13.0 & 13.0 & 12.0 & 11.6 & 10.9 & 12.1 \\
\hline
\end{tabular}

〈그림 2〉 국내 중형차시장 위상정립도

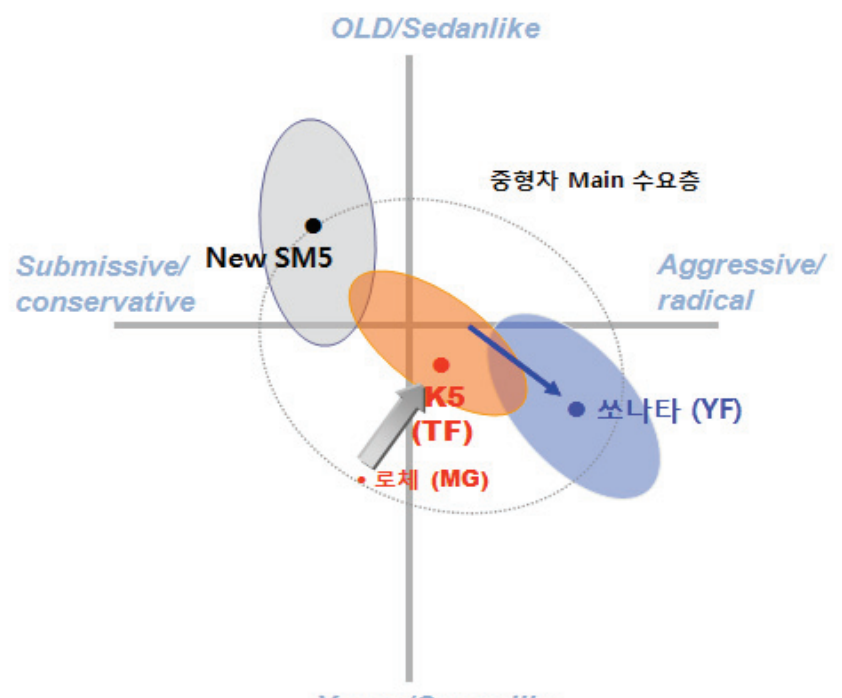

Young/Coupelike 
한 반응을 예측하는 것으로 국내에서도 활발히 이루어지고 있는데, 그 대표적인 예가 바로 기 아자동차의 베스트셀링 모델, $\mathrm{K} 5$ 이다. 기아자동 차는 알파벳 이니셜과 숫자의 조합을 통해 자 동차의 이름을 정하면서, 이미 다양한 이름이 혼재하는 상황에서 과연 어떠한 조합이 가장 좋은 반응을 이끌어낼까 하는 것이 주된 관심 사였다. 카이스트(KAIST) 신경 물리학 연구실 은 이 문제에 뉴로마케팅의 기법을 이용하였다. 다양한 알파벳-숫자 조합이 일으키는 순간적인 뇌의 반응을 $\mathrm{MRI}$ 와 안구 추적 장비를 이용하 여 살핀 것이다. 수십 명의 잠재 소비자를 대상 으로 한 이 연구는, 선호도와 관련된 것으로 알 려진 뇌 영역의 활동과 순간적인 눈의 움직임 을 분석하여, 최종적으로 알파벳 $\mathrm{K}$ 와 홀수 숫 자의 조합이 선택되는데 중요한 역할을 하였다. 특히 $\mathrm{K} 5$ 의 제품 컨셉은 $\mathrm{K}$ 의 다면적이고 함축 적인 의미를 통해서도 확인될 수 있다. $\mathrm{K}$ 는 기 아자동차가(Kia), 대한민국을 대표하는(Korea),
다른 차들을 압도하고 능가하는 강인함 및 지 배력을 지니고(Kratos), 끊임없이 혁신과 발전 을 추구하는 역동성(Kinetic)을 띈 제품을 개발 하겠다는 의미가 내재된 것이라 할 수 있다.

$\mathrm{K} 5$ 의 제품 우수성은 국내외 저명한 상들의 수상 실적들을 통해 엿볼 수 있다. 디자인 부문 과 안전성 부문에 걸쳐 자동차 관련 국내외의 저명한 상들을 다수 수상함으로써, 제품의 우수 성을 널리 알리고 있다(〈표 3〉참조).

\section{4 런칭 전략}

$\mathrm{K} 5$ 런칭 전략은 크게 네 가지 성공 포인트로 요약될 수 있다. 런칭 시점에 따른 단계별 차별 화된 광고 전략이 첫 번째 성공 포인트이다. $\mathrm{K} 5$ 는 런칭 시점에 따라 각기 다른 세 가지 광 고를 선보였다. 첫 단계는 모스 부호를 통해 소 비자의 호기심을 자극한 티저(teaser) 광고였다. 차량에 대한 설명 없이 $\mathrm{K} 5$ 에 대한 소비자의 호

〈표 3〉 K5 수상 내역

\begin{tabular}{|c|c|}
\hline Q日e & 세계 3대 디자인상인 $2011 \mathrm{iF}$ 디자인어워드 Winner (수송디자인 분야) \\
\hline & $\begin{array}{l}\text { 국내 최고권위의 } 2010 \mathrm{GOOD} \text { DESIGN 국무총리상 } \\
2010 \text { 소비자가 선정한 GD대상 }\end{array}$ \\
\hline $\begin{aligned} G O O D \\
D E S I G N\end{aligned}$ & 미국에서 가장 긴 역사의 2010 美 GOOD DESIGN AWARD 수상 (운송부문) \\
\hline & 미국 고속도로안전보험협회 (IIHS) 2011 Top Safety Pick Awards Winner \\
\hline & 한국 자동차기자협회 2011 올해의 차 2관왕 (대상/디자인상) \\
\hline
\end{tabular}


기심을 극대화 시키고자 하였다. 두 번째 단계 의 광고는 프리-런칭 광고로 $\mathrm{K} 5$ 의 출사표를 알 리는데 목적을 두었으며, 뉴욕을 배경으로 제작 된 광고는 제품의 품질이 세계적 수준에 도달 했으며, 세련된 인테리어와 첨단 사양을 노출시 킴으로써 소비자들에게 호기심과 기대감을 증 폭시켰다. 마지막으로 런칭 시점 이후의 광고에
서는 심플한 영상을 통해 브랜드에 대한 자신 감과 명확한 광고 메시지를 전달하였다. 이러한 세 단계 광고에서는 일관된 배경음악을 사용함 으로써 소비자들의 관심을 높은 수준으로 일관 되게 유도하고자 하였으며, 메시지 또한 명료하 게 전달되도록 하였다(〈표 4〉 참조).

둘째, 런칭 전 국내외 모터쇼를 신차 홍보의

〈표 4〉 K5의 시점별 광고 전략

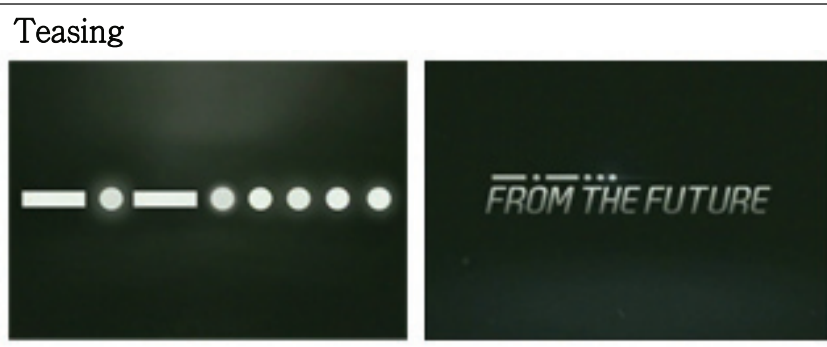

모스 부호- 중독성 강한 소리와 숨겨진 코드로 소비자의 호기심을 자극한 사운드 마케팅 $\Downarrow$

Pre-launching
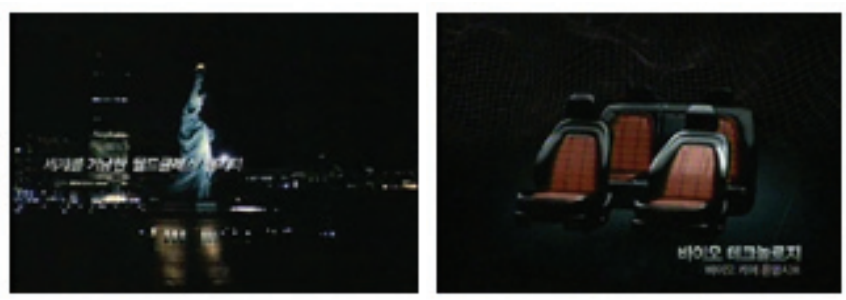

$\mathrm{K} 5$ 의 출사표

- 뉴욕이라는 도시가 주는 상징성을 활용, 세계적 수준의 품질에 대한 자신감 표출

- 세단의 미래를 구현한 핵심 첨단 사양 노출 $\Downarrow$

Launching

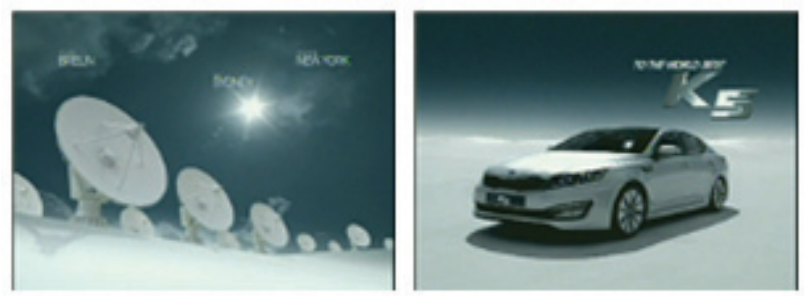

대한민국을 넘어 세계적·미래형 세단

- 심플한 영상을 통해 브랜드 자신감 표현

- 이해하기 쉬운 슬로건의 사용 
수단으로 적극 활용하였다. K5의 런칭 시점은 2010년 5월이다. 그러나 제품이 런칭되기 전 4 월 '뉴욕 모터쇼' 및 '부산 모터쇼'에서 이미 K5 는 그 자태를 뽐냈으며, 국내외 언론으로부터 극찬을 받게 된다. 특히 '뉴욕타임즈'와 '유에스 에이 투데이' 및 '보스톤 글로브'를 통해 디자인 우수성을 주목 받았으며, 해외에서의 관심은 국 내로의 관심으로 옮겨지게 되었다. 국내 소비자 들은 런칭 이전부터 $\mathrm{K} 5$ 의 우수성을 인지하였으 며, $\mathrm{K} 5$ 는 제품 출시와 동시에 중형차 시장의 새로운 강자로 등극하게 되었다.

셋째, $\mathrm{K} 5$ 는 기존 1 등 브랜드들과의 제휴를 통해 브랜드 이미지 및 인지도를 제고하고자 하였다. 삼성전자와의 제휴 마케팅 일환으로, 삼성전자 매장과 기아자동차 매장에서 삼성전 자의 '파브TV'와 ' $\mathrm{K} 5$ '를 동시에 디스플레이 하 였다. 또한 SK텔레콤과의 제휴를 통해 안드로 이드용 K5 어플리케이션을 개발하고 이를 소비 자들에게 제공함으로써, 젊은 소비자층에게 $\mathrm{K} 5$ 의 브랜드 인지도를 적극적으로 높이고자 하였다. 마지막으로 전략적으로 PPL(Product Placement) 을 활용하여 제품의 노출효과를 극대화하였다. $\mathrm{MBC}$ 의〈위대한 탄생〉과 $\mathrm{KBS}$ 의〈아테나〉 프 로그램에서 전략적으로 PPL함으로써, 기존의 광고 못지 않게 제품의 노출효과를 얻게 되었 다. 기존의 PPL은 TV프로그램 내용과는 상관 없이 제품이 소품형태로 잠깐씩 노출되었으나, $\mathrm{K} 5$ 는 $\mathrm{TV}$ 프로그램의 기획 단계부터 프로그램 스토리에 부합될 수 있도록 노출 장면과 빈도 가 전략적으로 계획되었다. 전략적인 PPL을 통 해 $\mathrm{K} 5$ 는 제품의 노출뿐만 아니라 기아자동차 브랜드의 인지도를 제고할 수 있었다.

이처럼 $\mathrm{K} 5$ 는 디자인 경영철학에서 발전한 적
극적인 조직 문화를 바탕으로 그 성공의 초석 을 다졌으며, 시장분석과 적절한 $\mathrm{STP}$ 를 활용하 여 소비자가 원하는 제품을 만들었다. 그리고 런칭 시점에 맞추어 전략적으로 매체를 활용함 으로써 브랜드와 제품의 인지도를 높일 수 있 었다. 브랜드 작명에 알파벳 이니셜을 이용하여 고객에게 다양한 의미의 $\mathrm{K}$ 를 느낄 수 있도록 하고, 뉴로마케팅을 통해 알파벳 $\mathrm{K}$ 와 잘 어울 리는 숫자의 조합을 찾아내고, 출시를 알리는 광고에 $\mathrm{K} 5$ 를 의미하는 모스 부호를 사용함으로 써, 고객들의 잠재의식 속에 자연스럽게 자리 잡을 수 있었던 것이다.

\section{III. 결론 및 제언}

$\mathrm{K} 5$ 는 전사적으로 강조해온 디자인 경영의 성 과물이라 할 수 있다. 디자인 경영 초기 단계에 서 SOUL을 통해 과감히 기존의 기아자동차 디자인 스타일에 혁신적인 변화를 시도하였으 며, $\mathrm{K} 5$ 를 통해 재정립된 디자인 정체성을 굳건 히 함과 동시에 기아자동차의 위상을 제고시킬 수 있었다. 현 시점에서 기아자동차는 몇 가지 과제들을 해결해야 할 것으로 생각된다.

첫째, 기아자동차만의 강력한 브랜드 퍼스낼 리티의 재정립이다. 최근 자동차 시장은 신차 출시가 활발하고 기술의 발달로 인해 차종간 품질 차이는 점차 줄어들고 있는 추세이다. 그 러므로 향후 기아자동차가 더욱 성공하기 위해 서는 기아자동차만이 갖고 있는 독창적인 가치 를 재정립하고, 소비자들에게 이러한 가치를 강 력하게 각인시킬 수 있어야 한다. 개별 차종의 
성공을 넘어서 기아자동차 브랜드가 소비자에 게 줄 수 있는 가치를 향상시키기 위한 지속적 인 노력이 필요하다. 최근 JD Power가 렉서스 에 제안한 '품질을 재정의 하고 그에 따른 차별 화된 가치를 제안하라는 컨설팅 결과는 비단 렉서스뿐만 아니라 모든 자동차 제조사가 고민 해야 할 문제이다. $\mathrm{K} 5$ 의 성공을 바탕으로 한걸 음 나아가 기아자동차의 차별화된 가치가 무엇 이며, 소비자가 원하는 품질가치를 어떻게 제안 (quality value proposition) 할 수 있을지 고민 해야 한다.

둘째, $\mathrm{K} 5$ 의 성공을 발판으로 $\mathrm{K}$ 시리즈를 어떻 게 성공적으로 확장시킬지에 대한 고려가 필요 하다. $\mathrm{BMW}$ 의 $3,5,7$ 시리즈가 상이한 고객층의 니즈를 충족시키기 위해 수직적 라인확장전략을 성공적으로 수립하고, 소비자들에게 차별화된 제 품 가치를 제안함에 따라 구매의향(willingness to pay)을 향상시킨 예를 참조하여(Draganska and Jain, 2005; Horsky and Nelson 1992), K5 또한 성공적인 수직적 라인확장전략을 수립하기 위한 고민과 노력이 필요한 시점으로 보인다.

셋째, $\mathrm{K} 5$ 의 후속 모델들을 통해, 어떻게 기아 자동차가 성공적으로 고급차 시장(near-luxury 또는 luxury 차 시장)에서 성공을 거둘 수 있 을지에 대한 고민이 더욱 필요하다. $\mathrm{K} 7$ 또는 $\mathrm{K}$ 시리즈의 프리미엄 버전의 차종으로 시장에 진 출할지, 아니면 새로운 기아자동차의 럭셔리 브 랜드 차종으로 고급차 시장에 진출할지에 대한 고민이 필요할 것으로 생각된다.

기아자동차 $\mathrm{K} 5$ 의 성공적인 포지셔닝 전략은 신 시장 개척을 위한 포지셔닝 전략을 계획하 고 있는 많은 기업에게 의미 있는 시사점을 제 공해 준다. 급변하는 자동차 산업을 선도할 기
아자동차의 활약상을 기대한다.

\section{참고문헌}

국내 중형차 시장 광고효과 조사(2010), TNS Korea.

Aaker, David A. and D. McLoughlin (2010), Strategic Market Management Global Perspectives, 1st edition. John Wiley \& Sons Ltd.

Atiyeh, C.(2010), In New York, automakers reveal optimism, The Boston Globe, Apr. 06, 2010.

Draganska, M. and Jain, D.C.(2005), "Product Line Length as a Competitive Tool," Journal of Economics and Management Strategy, 14(1), 1-28.

Horsky, D. and P. Nelson (1992), "New Brand Positioning and Pricing in an Oligopolistic Market." Marketing Science, 11(2), 133153.

Kurczewski, N.(2010), New York Auto Show: 2011 Kia Optima, The New York Times, Apr. 1, 2010.

Woodyard, C. (2010), Kia Optima becomes a swan in dramatic redesign, USA TODAY, Apr. 03, 2010. 


\title{
Successful Positioning Strategy of KIA K5 \\ - by understanding market needs -
}

\author{
Seo, Jiyoung* \\ Lee, Doo-Hee** \\ Lee, Jong-Ho*** \\ Jeon, Ki Heung****
}

\begin{abstract}
The objective of this case study is to analyze how effectively KIA K5, which is a leading mid-size car brand, has positioned itself into the mid-size car market. Before KIA launched the K5, Sonata and SM5 were the leading brands in the mid-size car market. They had loyal customers who like their similar images. As many competitors keep launching new brands or new designs into the car industry, Sonata and SM5 were pressured to introduce new versions. But, the YF Sonata and the New SM5 failed to catch up with the new trends in the market. Whilst YF Sonata was perceived as too innovative, the New SM5 was treated as an old car by the target customers of the mid-size car. While the two leading brands struggled to attract customers, KIA K5 found a new market space by identifying and focusing on the lucrative replace and up-grade demand segment and filling the gap between the current product category values and the emerging mid-size car category values. The K5 found the right values that customers need and successfully articulated the values to the customers. This case study illustrates that a successful positioning strategy can be effectively employed to attract customers in the saturated car manufacturing industry. This case can be summarized as the successful positioning strategy of KIA K5 is comprised of four primary pillars: design innovation, market analysis, STP (segmentation, targeting, and positioning), and launch strategy. The KIA K5 case study provides valuable insights and implications for many other companies that are planning to find a proper positioning strategy for their own business.
\end{abstract}

Key words: Design management, Positioning Strategy, Value proposition

\footnotetext{
* Ph.D. student, Korea University Business School, Korea University

** Professor, Korea University Business School, Korea University

*** Corresponding Author, Associate Professor, Korea University Business School, Korea University

**** Associate Professor, School of Business Administration, Jeonju University
} 